\section{Diallel analysis and genetic differentiation of tropical and temperate maize inbred lines}

\author{
Vania Portes Kulka1, Tereza Aparecida da Silva², Rodrigo I. \\ Contreras-Soto ${ }^{3,4^{*}}$, Carlos Maldonado5, Freddy Mora ${ }^{5}$ and \\ Carlos Alberto Scapim²
}

\begin{abstract}
This study aimed to evaluate hybrids obtained by the cross among temperate $\times$ tropical elite maize lines, and to determine the genetic diversity and population differentiation of these inbred lines. Forty-nine hybrids were evaluated for seed yield, plant and ear heights, and for severity of Phaeosphaeria maydis and Exserohilum turcicum in four environments in Brazil. Hybrids were obtained from a partial diallel that involved seven tropical and seven temperate lines. Twenty-two SSR primers were used to evaluate the genetic relationship among the lines. Diallel showed the existence of significance for GCA and SCA effects; the genetic control of the traits was associated with additive and nonadditive genetic effect. Results showed that exotic and previously protected temperate maize germplasm may provide novel alleles for resistance to $P$. maydis and E. turcicum and increase yield in tropical maize. Tropical inbred lines were allocated in different heterotic groups, suggesting an admixture condition among temperate and tropical materials.
\end{abstract}

Key words: Heterotic groups, general combining ability, specific combining ability, SSR.

\section{INTRODUCTION}

Maize breeding programs are based on the development and selection of hybrids obtained from inbred lines. This method is easy to perform; however, developing inbred lines with high performance is time-consuming. For this reason, and considering the high demand for maize around the world, government institutions and private companies have focused in developing superior hybrids with high performance and stable adaptation throughout different regions, climates, and sowing time. Thus, the available Brazilian maize germplasm collection has been used to increase the development of hybrids with high performance, high yield potential, and with stability and adaptability to different regions.

Exotic maize germplasm has been introduced to Brazil to increase the genetic variability and explore heterotic groups (Miranda Filho 1992). Consequently, the success of hybrid maize breeding depends crucially on the clustering of suitable germplasm in heterotic groups, and on the identification of high-yielding heterotic patterns. In fact, the heterotic patterns used for maize breeding program in the US Corn Belt have impacted breeding by largely predetermining the type of germplasm used in research programs over a long period of time (Reif et al. 2005).
Crop Breeding and Applied Biotechnology 18: 31-38, 2018 Brazilian Society of Plant Breeding. Printed in Brazil http://dx.doi.org/10.1590/1984$70332018 v 18 n 1 a 5$
E-mail: contrerasudec@gmail.com

Received: 08 November 2016 Accepted: 13 February 2017

${ }^{1}$ Melhoramento e Sementes Ltda, Saul Moreira Macedo, 31, 84.043-315, Ponta Grossa, PR, Brazil

${ }^{2}$ Universidade Estadual de Maringá (UEM), Departamento de Agronomia, Av. Colombo, 5790, 87.020-900, Maringá, PR, Brazil

${ }^{3}$ Universidad de O'Higgins, Instituto de Ciencias Agronómicas, Av. Libertador Bernardo O’Higgins 611, 28.20-000, Rancagua, Chile

${ }^{4}$ Centro de Estudios Avanzados en Fruticultura, Camino Las Parcelas 882 km 105 Ruta 5 Sur, Rengo, 29.40-000, Chile ${ }^{5}$ Universidad de Talca, Instituto de Ciencias Biológicas, Talca. 2 Norte, 685, Chile 


\section{VP Kulka et al.}

Currently, in the United States, the commercial maize hybrid (Zea mays L.) is being produced using patented inbred lines. Most of them are protected by the Plant Variety Protection (PVP) act since approximately 1970 (Mikel 2006). Mikel and Dudley (2006) evaluated these patented inbred lines and demonstrated that much of the American germplasm are represented by seven lines: B73, LH82, LH123, PH207, PH595, PHG39, and Mo17. The evaluated germplasm is separated into seven groups, according to the pedigree of the line, as follows: Oh43, Lancaster, Oh07-Midland, lodent, Stiff Stalk, Commercial hybrid derived, and Argentine Maiz Amargo backgrounds. In addition, after PVP patent expiration, these protected inbred lines become available for research and commercial applications, providing a new source of genetic diversity for breeding programs. Thus, to improve the use of this new germplasm, its characterization is necessary, in order to evaluate the relationship with other lines of existing germplasm (Nelson et al. 2008).

Although developments in phenotype and pedigree characterization associated with historical breeding progress have been well documented (Duvick et al. 2004), molecular markers have been widely used to study genetic diversity, to identity and characterize breeding material, as well as heterotic groups in maize and heterotic patterns for hybrid development (Laude and Carena 2015). Alternative methods to study genetic differentiation have been recently improved in plants, also known as artificial neural networks, which is based on the Self Organizing Map (SOM) algorithm (Barbosa et al. 2011). This method performs the clustering process by a hierarchical method that organizes from the highest to the lowest hierarchical level, resulting in a data set hierarchically ordered with the accuracy and robustness of a neural network (Herrero et al. 2003). The purpose of this study was to evaluate hybrids obtained between temperate $\times$ tropical elite maize lines and to determine the genetic diversity and the population differentiation of these lines by using SSR markers.

\section{MATERIAL AND METHODS}

\section{Maize inbred lines}

The tropical lines used in the present work belong to KWS Melhoramento e Sementes Ltda. and were developed from commercial hybrids by using classical breeding methods, i.e., by making several selfings until reaching a satisfactory level of homozygosity. The temperate lines were originated in the United States. These lines were protected for 20 years by the Plant Variety Protection Act of 1970; however, their protection certificate has expired, which means they can be used by public and private maize breeding programs. Table 1 shows a brief description of the inbred lines.

\section{Experimental diallel design and field performance evaluation}

To obtain hybrids, the lines were planted in Cambé-PR (lat 23 $14^{\prime} \mathrm{S}$, long $51^{\circ} 13^{\prime} \mathrm{W}$, alt $535 \mathrm{~m}$ asl) in January 2014. Lines of Group I (Tropical: L1, L2, L3, L4, L5, L6 and L7) were crossed with lines of Group II (Temperate: L1', L2', L3', L4', L5', L6' and L7'), generating 49 hybrids. Tropical lines were used as female parent and temperate lines were used as male parent.

The 49 hybrid combinations obtained in this study were evaluated in four sites: Campo Largo (lat $25^{\circ} 24^{\prime} \mathrm{S}$, long $49^{\circ} 29^{\prime} \mathrm{W}$, alt $1003 \mathrm{~m}$ asl), Castro (lat $24^{\circ} 43^{\prime} \mathrm{S}$, long $49^{\circ} 55^{\prime} \mathrm{W}$, alt $994 \mathrm{~m}$ asl), Mauá da Serra (lat $23^{\circ} 50^{\prime} \mathrm{S}$, long $51^{\circ} 12^{\prime}$ W, alt $949 \mathrm{~m}$ asl), and Ponta Grossa (lat $25^{\circ} 24^{\prime} \mathrm{S}$, long 49 $30^{\prime} \mathrm{W}$, alt $900 \mathrm{~m}$ asl) in the growing season of 2014/2015. Hybrids were arranged in a complete block design with three replications, and were planted in $5 \mathrm{~m}$ single row plots, spaced $0.75 \mathrm{~m}$ between rows, and $0.50 \mathrm{~m}$ between plants, at a population density of 74,500 plants ha ${ }^{-1}$. Fertilizer and field management practices recommended for optimum maize production were used in all the experiment sites.

Combined analyses of variance for each trait were performed according to the completely randomized block design, considering the effects of genotypes as fixed and the effects of sites as random. Genetic analysis was performed to estimate general combining ability (GCA), specific combining ability (SCA), and their interaction with the sites, by using the method 4 of Griffing (1956), model I, adapted for a partial diallel, by the method of Geraldi and Miranda Filho (1988), according to the following model:

$$
y_{i j}=\mu+g_{i}+g_{j}+s_{i j}+\varepsilon_{i j}
$$

Where: $y_{i j}$ : mean of hybrid combination between the $i^{\text {th }}$ inbred line of group I and the $j^{\text {th }}$ inbred line of group II. $\mu$ : Overall mean. $g_{i}$ : General combining ability effect of the $i^{\text {th }}$ inbred line. $g_{j}$ : General combining ability effect of the $j^{\text {th }}$ inbred 
line. $s_{i j}$ : Specific combining ability effect of the $i^{\text {th }}$ inbred line of Group I and $j^{\text {th }}$ inbred line of group II. $\varepsilon_{i j}$ error. Analyses were performed using the GENES software (Cruz 2013).

In each plot, plant height and ear height ( $\mathrm{PH}$ and $\mathrm{EH}$ ) were measured in $\mathrm{cm}$, taking the distance from the base of the plant to the height of the first tassel branch and to the insertion point of the upper ear, respectively. Severity of Phaeosphaeria maydis (PM) and Exserohilum turcicum (ET) was based on plant aspect, and was measured 30 days before flowering by using a grade scale ranging from 1 to 8 and 1 to 7 , respectively. For PM, the grades 1, 2, 3, 4, 5, 6, 7 and 8 , represent 1, 3, 6, 13, 25, 43, 63 and 79\% of severity (Sachs et al. 2011). For ET, severity of blotch was evaluated using the diagrammatic scale with grades that represent $0.5 ; 1.0 ; 2.5 ; 6.5 ; 15.5 ; 30$ and $54 \%$ of severity, according the above mentioned scale (Lazaroto et al. 2012). Grain yield (GY) (in ton ha-1) was adjusted to $13 \%$ moisture.

\section{DNA extraction and SSR analysis}

Leaves of seven tropical and seven temperate inbred lines were sampled from five young maize plants, totaling seventy samples. DNA extraction was done using the modified CTAB procedure (Hoisington et al. 1994), with minor modifications. Twenty two SSR primers previously mapped for maize were obtained from the maize germplasm bank (http://www.maizegdb.org.php) and used to test all the fourteen inbred maize lines (70 samples). PCR (Polymerase Chain Reaction) was performed according to Lopes et al. (2015), using the Touchdown-PCR for SSR amplification (Don et al. 1991). The size of the fragments was determined using a 100 bp DNA ladder and visualized through electrophoresis.

\section{Genetic diversity and analysis of molecular variance (AMOVA)}

Genetic diversity of 14 maize inbred lines was analyzed with 22 SSR markers by using the GenAlex software. The following genetic diversity parameters were studied: total number of alleles per locus ( $\mathrm{Na}$ ), observed and expected heterozygosity denoted by (Ho) and (He), respectively, and polymorphic information content (PIC) (Peakall and Smouse 2007).

Analysis of molecular variance was carried out using the poppr package. In addition, to test if populations were significantly different, a randomization test was performed using the function randtest of the ade4 package (Kamvar et al. 2014).

\section{Population structure and genetic relationship}

Population structure was estimated under the Markov Chain Monte Carlo (MCMC) algorithm for the generalized Bayesian clustering method implemented in the InStruct software (Gao et al. 2007). Consequently 10 independent runs of MCMC sampling were implemented for numbers of groups (K parameter), varying from 2 to 5 . For each run, the initial burn-in period was set to 10,000 with 110,000 MCMC iterations, under the non-admixture model, and with without prior information on the individual's origin. Among the four K simulated groups, the lowest value of Deviance Information Criterion (DIC) was considered to determinate the most probable K value (Gao et al. 2007). This method does not assume the Hardy-Weinberg equilibrium within loci, and the expected genotype frequencies are estimated based on the rates of inbreeding or selfing.

Additionally, population structure was evaluated using the Self-Organizing Tree Algorithm (SOTA), which represents an unsupervised artificial neural networks approach implemented in the R software (Brock et al. 2008). The data used in SOTA was the population allelic frequencies obtained from GenAlex (Peakall and Smouse 2007). The Euclidean distance was used to represent the metric applied in the calculation of dissimilarities between profiles. In addition, the Unweighted Neighbor-Joining algorithm with a simple matching dissimilitude coefficient with 10,000 bootstrapping samples was implemented using the DARwin 6.0.13 software (Perrier and Jacquemoud-Collet 2006).

\section{RESULTS AND DISCUSSION}

Statistically significant differences among genotype means were reported for all traits under study $(\mathrm{P}<0.01)$. Similarly, the F1's $\times$ sites interaction showed significant differences (Mean Squares significant for: $\mathrm{PH}=137.5(\mathrm{~cm}) ; \mathrm{EH}=56.9(\mathrm{~cm})$;

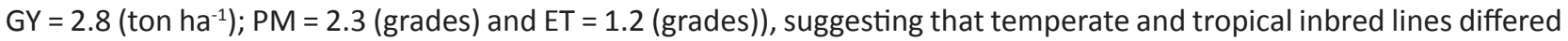
in relation to all traits evaluated among the sites. In fact, this indicates that each site should be individually analyzed. 
Table 1. Origin and type of grain of tropical (Group I) and temperate (Group II) inbred lines of Zea mays

\begin{tabular}{lcccc}
\hline Lines & Origin & Type of grain & Cycle & Adaptation \\
\cline { 2 - 3 } & Group I - Tropical Lines & Flint & Late & Tropical \\
L1 & Synth. Cargill 1 & Flint & Early & Subtropical \\
L3 & Synth. Cargill 2 & Semi Flint & Super-Early & Subtropical/Temperate \\
L4 & Synth. Cargill 3 & Flint & Late & Tropical \\
L5 & Synth. Pioneer 1 & Semi Flint & Early & Subtropical \\
L6 & Synth. Pioneer 2 & Semi Dent & Medium & Subtropical \\
L7 & Synth. Pioneer 3 & Semi Flint & Early & Subtropical \\
\hline Group II - Temperate Lines & Synth. Embrapa 1 & & & \\
\hline B73 (L1') & & Semi Dent & - & Temperate \\
MO17 (L2') & Stiff Stalk Synthetic & Dent & Temperate \\
LH82 (L3') & Lancaster & Dent/Semi Dent & - & Temperate \\
LH123 (L4') & Derived of commercial hybrid & Semi Dent & - & Temperate \\
PH207 (L5') & Derived of commercial hybrid & Dent & Temperate \\
PHG39 (L6') & lodent & Semi Dent & Temperate \\
PHV78 (L7') & Maiz Amargo & Dent & Temperate \\
\hline
\end{tabular}

Partial diallel cross provides estimates of GCA and SCA for a specific set of lines, and this analysis has been used to evaluate the combining ability and performance of several maize lines with respect to many traits (Henry et al. 2014). The present results, which evaluated the cross between temperate $\times$ tropical materials, were significant for GCA and SCA effects, suggesting additive gene action in the control of the traits SY, PH, EH, PM and ET. The percentages of contribution of the GCA effect were higher than that of the SCA effect for all the five traits evaluated. PH, EH, GY, PM and ET showed $96.17 \%, 92.86 \%, 91.96 \%, 94.04 \%$ and $87.79 \%$ of the contribution of the GCA effects, respectively, indicating the importance of additive gene action and high frequency of favorable alleles controlling the five traits studied (Table 2). Studies that aimed at investigating the combining ability in tropical and temperate maize lines were significant for GCA and SCA for the agronomic traits of interest, such as grain yield and plant height (Henry et al. 2014, Werle et al. 2014). Specifically, Henry et al. (2014) showed that the additive effects were more important than the non-additive effects for PH, confirming the present results. Similarly, for P. maydis and E. turcicum, some studies have demonstrated the importance of additive effects controlling these traits (Vivek et al. 2010). Conversely, for SY, contrasting results have been reported, revealing the importance of additive and non-additive effects controlling this trait (Henry et al. 2014, Werle et al. 2014). Given the importance of GCA in all traits, exotic, previously protected temperate maize germplasm may provide novel alleles for resistance to $P$. maydis and $E$. turcicum, which have not been observed in tropical maize materials. Similarly, to improve agronomic important traits, this germplasm may serve as a source of new alleles to increase yield and stabilize production.

The effects of the GCA I $\times$ sites, GCA II $\times$ sites, and SCA $\times$ sites interactions were all significant at $5 \%$ probability, suggesting that the GCA and SCA effects should be analyzed by site (Table 2). Previous reports have also showed highly significant $=$ GCA $x$ site and SCA $x$ site interactions for traits of agronomic importance and for diseases in maize (Henry et al. 2014).

Variation sources of treatments, hybrids (F1's) and between groups were significant for all variables studied, indicating high genetic divergence among the inbred lines. These results are relevant, since lines that represent heterotic groups adapted to different environments are highly required, which should be investigate for grain yield and disease resistance, in order to produce hybrids with a high degree of genetic diversity. Specifically, this is interesting from the breeding perspective, since these patterns of diversity can be used in the development of adapted germplasm by the Brazilian maize breeding program by using these temperate exotic germplasm.

Hybrids $\times$ sites showed significant differences for all evaluated traits, suggesting a different behavior for all traits among the sites (Table 2). According to Troyer (1996), the significant effects of single hybrids and sites interaction are frequently tested because the narrow genetic base of single hybrids allows for a stronger differential response to the 
Table 2. Summary of joint analyses of variance for plant height and ear height evaluated in three sites, and for grain yield, severity of Phaeosphaeria maydis and Exserohilum turcicum evaluated in four sites in Brazil during the growing season of 2014/2015

\begin{tabular}{|c|c|c|c|c|c|c|c|}
\hline \multirow[b]{2}{*}{ Source of variation } & \multirow[b]{2}{*}{ df } & \multicolumn{2}{|c|}{ Mean squares } & \multirow[b]{2}{*}{ df } & \multicolumn{3}{|c|}{ Mean squares } \\
\hline & & $\begin{array}{c}\text { PH } \\
(\mathrm{cm})\end{array}$ & $\begin{array}{c}\text { EH } \\
(\mathrm{cm})\end{array}$ & & $\begin{array}{c}\text { GY } \\
\left(\text { ton ha }{ }^{-1}\right)\end{array}$ & $\begin{array}{c}\text { PM } \\
\text { (grades) }\end{array}$ & $\begin{array}{c}\text { ET } \\
\text { (grades) }\end{array}$ \\
\hline Blocks/sites & 6 & 1126.39 & 391.03 & 8 & 11.74 & 1.33 & 1.81 \\
\hline Sites & 2 & 130098.59* & $47898.81^{*}$ & 3 & $425.24^{*}$ & $38.05^{*}$ & $475.32^{*}$ \\
\hline Treatments & 51 & $3063.27^{*}$ & $1800.17^{*}$ & 51 & $33.62^{*}$ & $15.32^{*}$ & $8.69 *$ \\
\hline$F_{1}^{\prime} s$ & 48 & $3193.35^{*}$ & $1742.32 *$ & 48 & $25.44^{*}$ & $15.26^{*}$ & $7.64^{*}$ \\
\hline Treatments $x$ Sites & 102 & $137.47^{*}$ & $56.23^{*}$ & 153 & $3.09 *$ & $2.26 *$ & $1.21 *$ \\
\hline F1's $\times$ Sites & 96 & $137.53 *$ & $56.86^{*}$ & 144 & $2.81^{*}$ & $2.33^{*}$ & $1.18^{*}$ \\
\hline Control $\times$ Sites & 4 & 63.65 & 45.04 & 6 & $3.09 *$ & $1.34^{*}$ & 0.03 \\
\hline Between groups $\times$ Sites & 2 & $282.06^{*}$ & 48.45 & 3 & $16.59 *$ & $0.49 *$ & $4.92 *$ \\
\hline Error & 306 & 58.10 & 29.76 & 408 & 1.31 & 0.17 & 0.22 \\
\hline $\mathrm{CV}(\%)$ & & 3.04 & 4.23 & & 9.08 & 21.77 & 19.93 \\
\hline
\end{tabular}

* F test significant at $5 \%$ probability. $\mathrm{PH}=\mathrm{Plant}$ height; $\mathrm{EH}=$ Exserohilum turcicum; $\mathrm{GY}=\mathrm{Grain}$ yield; $\mathrm{PM}=$ Phaeosphaeria maydis; $\mathrm{EH}=$ Ear height.

evaluation sites, when compared with double hybrids or cultivars with a broader genetic base.

In maize breeding programs, greater plant height is not a desired trait. The identification of lines with negative GCA value for plant height and high GCA value for grain yield would be beneficial for a breeding program that aims at increasing plant yield. The lines L4, L4' and L7' showed positive GCA for grain yield $\left(\hat{\mathrm{g}}_{\mathrm{i}}=1.309 ; 1.007\right.$ and 1.241 , respectively) and should be promising for Brazilian maize breeding programs. In fact, L4 $\times \mathrm{L7}^{\prime}\left(\hat{\mathrm{S}}_{\mathrm{ij}}=0.415\right), \mathrm{L} 4 \times \mathrm{L} 4^{\prime}\left(\hat{\mathrm{S}}_{\mathrm{ij}}\right.$ $=0.392)$ and $\mathrm{L} 7 \times \mathrm{LT}^{\prime}\left(\hat{\mathrm{S}}_{\mathrm{ij}}=0.583\right)$ were high-yielding hybrid indicated for new evaluations in other sites, aiming at a possible commercial hybrid. Interestingly, $L 4$ temperate line, and $\mathrm{L}^{\prime}$ ' and $\mathrm{L} \mathbf{7}^{\prime}$ tropical lines were subdivided into strongly differentiated genetic groups, according to the results of the bayesian population structure (Figure 1). Laude and Carena (2015) state that classifying variable genotypes into homogeneous groups based on their genetic relationships and similarities increases the efficiency in planning crosses for a breeding program. Reif et al. (2005), for instance, observed that hybrid performance was higher when parents are genetically diverse.

Northern corn leaf blight (NCLB), caused by the pathogen E. turcicum, is a worldwide severe fungal disease that results in yield losses. According to Dingerdissen et al. (1996), it can be efficiently controlled by resistant varieties. In the present study, the lines $L 4^{\prime}\left(\hat{\mathrm{g}}_{i}=-1.107\right)$ and $L 7^{\prime}\left(\hat{\mathrm{g}}_{i}=-0.393\right)$ showed the lowest values of GCA for $E$. turcicum among all the sites, suggesting the putative resistance of these lines. Resistance to NCLB is generally classified as: major gene resistance, conferred by the $\mathrm{Ht} 1, \mathrm{Ht} 2, \mathrm{Ht} 3$ or $\mathrm{HtN}$ genes, which is race specific; or partial resistance, which is controlled by polygenic genes and is effective against all pathogen biotypes (Carson 2006). Brazilian populations of E. turcicum seem to be more diverse than North American races in terms of race composition (Ogliari et al. 2005). Gianasi et al. (1996) observed a predominance of race 0 , but also detected races capable of overcoming resistance conferred by the Ht1gene (races $1 \mathrm{~N}, 12 \mathrm{~N}$, and $123 \mathrm{~N}$ ). Since the susceptibility of most of the most susceptible hybrids was similar in all the evaluated sites, it was impossible to differentiate the presence of different races. However, in Maúa da Serra, 
greater influence of the disease severity level was observed (Severity of E. turcicum Maúa da Serra=4.1; Ponta Grossa and Campo Largo=1.1 and Castro=2.6), suggesting this site as the most appropriate for selection of hybrids resistant to $E$. turcicum in maize.

Several studies showed that both GCA and SCA effects were significant for $P$. maydis, with GCA accounting for higher variation than SCA effect (Sibiya et al. 2011). These results were confirmed, since some resistant hybrids involved a susceptible and a resistant parent, where at least one of the parents had a negative GCA effect (i.e., $L 1 \times L 1^{\prime}\left(\hat{S}_{i j}=\right.$ -0.640) in Ponta Grossa; L3 x L6' in Ponta Grossa and Mauá da Serra $\left(\hat{S}_{\mathrm{ij}}=-0.450\right.$ and $\hat{\mathrm{S}}_{\mathrm{ij}}=-1.248$, respectively); L6 $\times$ L2' $\left(\hat{S}_{i j}=-0.921\right)$ in Mauá da Serra; L6 x L3' in Campo Largo and Mauá da Serra $\left(\hat{S}_{\mathrm{ij}}=-0.694\right.$ and -0.684 , respectively)). These results confirmed the presence of non-additive gene action. The tropical lines L1 ( $\hat{\mathrm{g} i}=-0.748$ ) and L6 ( $\mathrm{g} i=-1.058$ ) showed potential to be used in breeding programs, since an increase in resistance was observed among all the sites evaluated. In addition, these lines can be used in specific crosses for the development of hybrids resistant to $P$. maydis. These results are important, since Phaeosphaeria leaf spot (PLS) is more prevalent in areas of high rainfall and moderate temperatures, as it occurs at higher elevations in the tropics. In addition, the present result should be considered as of great importance, specifically for tropical areas with altitudes above $600 \mathrm{~m}$, since favorable conditions for the development of $P$. maydis prevail in the states of São Paulo, Minas Gerais and Goiás.

According to Carson (1999), B73 line $\left(L 1^{\prime}, \hat{g} \mathrm{i}=0.740\right)$ and its derivatives were particularly susceptible to PLS, corroborating the present results. However, most of the temperate germplasm base of the U.S. maize hybrids are highly resistant to PLS (Carson 2006). Carson (1999) suggests that PLS has late development at the grain-filling stage; consequently, its potential to cause substantial losses in the United States is limited. In the present study, among the temperate lines, PHG39 (L6', Maiz Amargo, ĝi = -0.939) showed the lowest GCA values among all environments. In addition, LH123 (L4' in Ponta Grossa, Campo Largo and Castro with ĝi $=-0.408$; -0.354 and -0.244 , respectively) and PHV78 (L7' in Campo Largo, Castro and Mauá da Serra with ĝi $=-0.543 ;-0.436$ and -1.225 , respectively) were particularly resistant in some environment, and contributed with hybrids that showed resistant to PLS. In fact, these temperate inbred lines should be indicated as potential parent to improve resistance of hybrid under tropical conditions.

Polymorphism of SSR markers among the fourteen maize inbred lines revealed a total of 65 putative alleles. The observed heterozygosity had slight difference among the SSR, and most of the values were equal to zero (eighteen markers: UMC1072; MMC0501; UMC1636; UMC2059; UMC1336; UMC1137; UMC1642; UMC2205; UMC2164; UMC1069; BNLG1927; UMC1397; UMC1506; UMC2267; UMC2308; BNLG1367; UMC2280 and UMC2198) with mean=0.0009, which means that more than $80 \%$ of the loci were fixed and reached considerable homozygous levels. Consequently, the study showed that SSR markers can be used to discriminate temperate from tropical inbred lines. The polymorphic information content values for all markers indicated that most of the markers used had high discriminatory power and are useful for genetic diversity studies (varying from UMC2267=0.28 to UMC1506=0.69 and mean=0.47). In fact, molecular markers have provided a more reliable differentiation of genotypes, allowing the establishment of inbred lines into distinct cluster of genotypes, based on the discrimination power of the marker and on the genetic distance of genotypes (Richard et al. 2016). AMOVA revealed significant differentiation between the inbred lines, explaining $96 \%$ of the total variance. Remaining variance was divided between sources of variation: samples between and within lines ( 2.65 and 1.13 , respectively). Consequently, the present study revealed significant differentiation between the tropical 
and temperate inbred lines, with admixed population structure among the tropical and temperate inbred lines.

Mikel and Dudley (2006) mentioned that much of today's maize germplasm are originated from seven progenitor lines: B73, Mo17, PH207, PHG39, LH123Ht, LH82, and PH595. Nelson et al. (2008), by using UPGMA cluster analysis, revealed six predominant clusters that were represented by the following lines: B73, Mo17, PH207 (Iodent), A632, Oh43, and B37. However, several commercial hybrid lines, or unrelated genetic material fail to cluster with any one of the aforementioned groups (Richard et al. 2016). The separation of inbred lines into temperate and tropical groups is commonly reported in molecular diversity studies (Laude and Carena 2015, Richard et al. 2016). Thus, as identified in other studies, it was expected that the seven prominent USA inbred lines (Mo17, PH207, B73, LH82, LH123, PHG39, and PHV78) would form individual clusters. Nevertheless, according to the bayesian clustering analysis, the most probable number of subpopulations was two, and an admixture condition was reported for these lines (i.e., Mo17 were grouped with LH207 and LH82; B73 were grouped with PHG39). Moreover, cluster analysis separated the tropical inbred lines and the admixed with the temperate heterotic groups (Figure 1). Similarly, the approach based on artificial neural networks inferred two strongly differentiated groups. In addition, results based on unweight Neighbor-Joining algorithm are in agreement with those predicted by SOTA (Figure 2).

Other studies have clustered the temperate heterotic lines into lowa Stalk Synthetic and Lancaster heterotic groups (Richard et al. 2016). These results corroborate the idea of PVPA certificates, which indicates that some of the ex-PVPA inbred lines are ambiguous, incomplete, erroneous, or include progenitors of an undisclosed origin (Nelson et al. 2008).

\section{REFERENCES}

Barbosa CD, Viana AP, Quintal SSR and Pereira MG (2011) Artificial neural network analysis of genetic diversity in Carica papaya L. Crop Breeding and Applied Biotechnology 11: 224-231.

Brock G, Pihur V, Datta S and Datta S (2008) clValid, an R package for cluster validation. Journal of Statistical Software 25: 1-22.

Carson ML (1999) Vulnerability of U.S. maize germplasm to Phaeosphaeria leaf spot. Plant Disease 83: 462-464.

Carson ML (2006) Response of a maize synthetic to selection for components of partial resistance to Exserohilum turcicum. Plant Disease 90: 910-914.

Cruz CD (2013) GENES: A software package for analysis in experimental statistics and quantitative genetics. Acta Scientiarum. Agronomy 35: 271-276.

Dingerdissen A, Geiger H, Lee M, Scheckert A and Welz H (1996) Interval mapping of genes for quantitative resistance of maize to Setosphaeria turcica, cause of northern leaf blight, in a tropical environment. Molecular Breeding 2: 143-156.

Don RH, Cox PT, Wainwright BJ, Baker K and Mattick JS (1991) Touchdown PCR to circumvent spurious priming during gene amplification. Nucleic Acids Research 19: 4008-4008.

Duvick DN, Smith JSC and Cooper M (2004) Long-Term Selection in a Commercial Hybrid Maize Breeding Program. Plant Breeding Reviews 24: 109-151.

Gao H, Williamson S and Bustamante CD (2007) A Markov Chain Monte Carlo approach for joint inference of population structure and inbreeding rates from multilocus genotype data. Genetics 176 : 1635-1651.

Geraldi IO and Miranda Filho JB (1988) Adapted models for the analysis of combining ability of varieties in partial diallel crosses. Revista Brasileira de Genética 11: 419-430.

Gianasi L, Castro HA and Silva HP (1996) Raças fisiológicas de Exserohilum turcicum identificadas em regiões produtoras de milho no Brasil, Safra 93/94. Summa Phytopathologica 22: 214-217.

Griffing JB (1956) Concept of general and specific combining ability in relation to diallel systems. Australian Journal Biological Science 9: 463-493.

Henry WB, Blanco MH, Rowe DE, Windham GL, Murray SC and Williams WP (2014) Diallel analysis of diverse maize germplasm lines for agronomic characteristics. Crop Science 54: 2547-2556.

Herrero J, Al-Shahrour F, Diaz-Uriarte R, Mateos A, Vaquerizas JM, Santoyo J and Dopazo J (2003) GEPAS: A web-based resource for microarray gene expression data analysis. Nucleic Acids Research 31: 3461-3467.

Hoisington D, Khairallah M and González-Léon D (1994) Laboratory Protocols: CIMMYT. Applied Molecular Genetics Laboratory. CIMMYT, Mexico DF, 50p.

Kamvar ZN, Tabima JF and Grünwald NJ (2014) Poppr: an R package for genetic analysis of populations with clonal, partially clonal, and/or sexual reproduction. PeerJ 2: e281.

Laude TP and Carena MJ (2015) Genetic diversity and heterotic grouping of tropical and temperate maize populations adapted to the northern US Corn Belt. Euphytica 204: 661-677.

Lazaroto A, Santos I, Konflanz VA, Malagi G and Camochena RC (2012) Escala diagramática para avaliação de severidade da helmintosporiose comum em milho. Ciência Rural 42: 2131-2137.

Lopes A, Scapim CA, Machado MFPS, Mangolin CA, Silva TA, Cantagali LB, Teixeira FF and Mora F (2015) Genetic diversity assessed by microsatellite markers in sweet corn cultivars. Scientia Agricola 72: 


\section{VP Kulka et al.}

$513-519$.

Mikel MA (2006) Availability and analysis of proprietary dent corn inbred lines with expired U.S. Plant Variety Protection. Crop Science 46: 2555-2560.

Mikel MA and Dudley JW (2006) Evolution of north american dent corn from public to proprietary germplasm. Crop Science 46: 1193-1205.

Miranda Filho JB (1992) Exotic germplasms introduced in a Brazilian maize breeding program. Brazilian Journal Genetics 15: 631-642.

Nelson PT, Coles ND, Holland JB, Bubeck DM, Smith S and Goodman M (2008) Molecular characterization of maize inbreds with expired U.S. Plant Variety Protection. Crop Science 48: 1673-1685.

Ogliari JB, Guimarães MA, Geraldi 10 and Camargo LEA (2005) New resistance genes in the Zea mays L. - Exserohilum turcicum pathosystem. Genetic Molecular Biology 28: 435-439.

Perrier X and Jacquemoud-Collet JP (2006) DARwin software. Available at <http://darwin.cirad.fr/darwin>. Accessed in August 2016

Peakall R and Smouse PE (2007) GENALEX 6: genetic analysis in Excel. Population genetic software for teaching and research. Molecular Ecology 6: 288-295.

Reif JC, Hallauer AR and Melchinger AE (2005) Heterosis and heterotic patterns in maize. Maydica 50: 215-223.
Richard C, Osiru D, Mwala M and Lubberstedt T (2016) Genetic diversity and heterotic grouping of the core set of southern African and temperate maize (Zea mays L) Inbred lines using SNP markers. Maydica 61: 1-9.

Sachs PJD, Neves CSVJ, Canteri MG and Sachs LG (2011) Escala diagramática para avaliação da severidade da mancha branca em milho. Summa Phytopathologica 37: 4.

Sibiya J, Tongoona P, Derera J, Van Rij N and Makanda I (2011) Combining ability analysis for Phaeosphaeria leaf spot resistance and grain yield in tropical advanced maize inbred lines. Field Crop Research 120: 86-93.

Silva HP and Moro JR (2004) Diallel analysis of maize resistance to Phaeosphaeria maydis. Scientia Agricola 61: 36-42

Troyer AF (1996) Breeding widely adapted, popular maize hybrids. Euphytica 92: 163-174.

Vivek B, Odongo O, Njuguna J, Imanywoha J, Bigirwa G, Diallo and Pixley K (2010) Diallel analysis of grain yield and resistance to seven diseases of African maize (Zea Mays L.) inbred lines. Euphytica 172: 329-340.

Werle AJK, Ferreira FRA, Pinto RJB, Mangolin CA, Scapim CA and Gonçalves LSA (2014) Diallel analysis of maize inbred lines for grain yield, oil and protein content. Crop Breeding and Applied Biotechnology 14: 23-28. 